\title{
NACIONALISMOS Y DERECHOS DE LOS MIGRANTES INTERNACIONALES EN EL TERRITORIO ARGENTINO: EL CASO DE LA CIUDAD AUTÓNOMA DE BUENOS AIRES
}

\author{
Anahí Patricia González
}

\section{RESUMEN}

ESTE ARTíCULO ABORDA EL TEMA DEL RECONOCIMIENTO Y EL ACCESO A LOS DERECHOS DE LOS MIGRANTES INTERNACIONALES QUE HABITAN EN ARGENTINA. ESPECÍFICAMENTE, SE ANALIZA LAS DECISIONES JUDICIALES DEL TRIBUnal Superior dE Justicia dE LA CIUdAd AUtÓnOMA DE BUENOS AIRES (TSJ BAIRES) RESPECTO AL DERECHO AL TRABAJO Y AL EJERCICIO DE LA DOCENCIA DE MAESTROS EXTRANJEROS. SE EFECTÚA EL ANÁLISIS DESDE UNA PERSPECTIVA SOCIOLÓGICA, YA QUE SE HA FOCALIZADO EN LAS REPRESENTACIONES SOCIALES QUE SE PUEDEN RASTREAR EN LA SENTENCIA. EN SUMA, SE HA LOGRADO EVIDENCIAR QUE LA MIRADA DE LA MAYORÍA DE LOS JUECES INTERVINIENTES EN EL CASO SE ENCUENTRA CARGADA DE ELEMENTOS NACIONALISTAS (DE TIPO CULTURALISTA Y CONSTITUCIONALISTA), QUE OBSTACULIZAN GARANTIZAR EL ACCESO DE LOS MIGRANTES INTERNACIONALES AL DERECHO EN CUESTIÓN.

\section{PALABRAS CLAVE}

MigRANTES; DERECHOS; ARgentinA; REPRESENTACIONES SOCIALES; NACIONALISMO.
NATIONALISMS AND RIGHTS OF INTERNATIONAL MIGRANTS IN THE ARGENTINE TERRITORY: THE CASE OF THE AUTONOMOUS CITY OF BUENOS AIRES

\begin{abstract}
THIS ARTICLE DISCUSSES THE ISSUE OF RECOGNITION AND ACCESS TO THE RIGHTS OF INTERNATIONAL MIGRANTS LIVING IN ARGENTINA. SPECIFICALLY, IT DISCUSSES THE JUDICIAL DECISIONS OF THE SUPERIOR COURT OF JUSTICE OF THE AUTONOMOUS CITY OF BUENOS AIRES (TSJ BAIRES) WITH REGARD TO THE RIGHT TO WORK AND EXERCISE OF THE TEACHING OF FOREIGN TEACHERS. THE ANALYSIS IS CARRIED OUT FROM A SOCIOLOGICAL PERSPECTIVE, SINCE IT HAS BEEN FOCUSED ON THE SOCIAL REPRESENTATIONS THAT CAN BE TRACKED IN THE SENTENCE. IN SHORT, IT HAS ACHIEVED TO DEMONSTRATE THAT THE LOOK OF THE MAJORITY OF THE JUDGES INTERVENERS IN THE CASE IS LOADED WITH NATIONALISTIC ELEMENTS (OF TYPE CULTURALIST AND CONSTITUTIONALIST) THAT PREVENTS TO GUARANTEE THE ACCESS OF THE INTERNATIONAL MIGRANTS TO THE RIGHT IN QUESTION.
\end{abstract}

\section{KEYWORDS}

MIGRANTS; RIGHTS; ARGENTINA; SOCIAL REPRESENTATIONS; NATIONALISM.

\section{INTRODUCCIÓN}

Las migraciones no son un fenómeno nuevo para Argentina. Ya a fines del siglo XIX y comienzos del siglo XX se producen las olas migratorias de mayor envergadura, 
fundamentalmente provenientes de Europa, en particular italianos y españoles (DEVOTO, 2003, p. 247). Paulatinamente, estas migraciones fueron dejando lugar a las regionales. Así, a partir de la segunda mitad del siglo XX, se modifica la cantidad y el origen de los migrantes internacionales que arriban al territorio, manteniéndose, en el tiempo, el aumento numérico progresivo de extranjeros de países limítrofes frente a los de países extrarregionales. Con todo, el porcentaje de migrantes históricamente, nunca ha superado el 5\%, en relación a la población total.

Particularmente, a partir de la década del noventa, se profundizan los procesos de concentración de la riqueza a consecuencia de medidas (tales como la privatización de sectores fundamentales de la economía y la desregulación de los mercados) que afectarían la estructura productiva y social del país, trayendo consigo altos niveles de desempleo, marginalidad, exclusión y fragmentación social (PUCCIARELLI, 1999, p. 29-38). En este escenario, surgieron, desde diversos espacios, discursos discriminatorios que culpabilizaban de todos los "males" de la sociedad argentina a los extranjeros. Estos discursos, que se reproducían desde instancias gubernamentales, sindicatos, partidos políticos, medios masivos de comunicación, etc., obtuvieron un amplio consenso en la sociedad y permitieron que las causas estructurales asociadas con aquel específico modo de acumulación, que se desarrollaba, quedaran ocultas (GONZÁLEZ; PLOTNIK, 2011, p. 35).

Con el correr de los años, luego del gobierno y la caída posterior del mandato del presidente Fernando de la Rúa en el 2001, comienza un proceso de reconfiguración económica y social del país. En materia migratoria, empieza a atenuarse, al menos desde instancias gubernamentales, aquel discurso que culpabilizaba al extranjero de los altos niveles de desempleo y de la inseguridad, entre otros tantos flagelos sociales. Por otra parte, a nivel normativo, se produce un hecho fundamental. En el año 2003 se deroga la denominada "Ley Videla" que, sancionada durante la Dictadura Militar, regía las cuestiones ligadas al derecho migratorio. Dicha norma, atravesada por la Doctrina de Seguridad Nacional, negaba una serie de derechos a los migrantes y, al tiempo que incentivaba la llegada de la inmigración europea, establecía disposiciones restrictivas para los migrantes de países limítrofes. En ese marco, una de las herencias de dicha ley, aun luego de muchos años del retorno de la democracia, sería la potestad de las fuerzas represivas para detener a cualquier migrante que no tuviera documentación sin ningún tipo de intervención judicial, incumpliéndose así garantías básicas del Estado de Derecho. Asimismo, el Ministerio del Interior estaba facultado para expulsar a todo extranjero "cualquiera [que] sea su situación de residencia" cuando fuere condenado por juez argentino por delito doloso con pena mayor de 5 años o realizare en el país o en el extranjero actividades que afecten la paz social, la seguridad nacional o el orden público.

Finalmente, la "Ley Videla” será reemplazada en el 2004 por la Ley n. 25871. Imbuida por una perspectiva de Derechos Humanos, la norma reconoce una serie de 
derechos fundamentales a los extranjeros. Ahora bien, este cambio de normativa debe ser considerado como un punto de partida interesante para la discusión acerca de los derechos de los migrantes. No obstante, el trabajo de litigio y de concientización acerca de la ley, que se encuentra aún en proceso, es fundamental. Es en este sentido que el análisis de las representaciones ${ }^{1}$ de diversos actores sociales, sobre todo de aquellos que forman parte del Poder Judicial como institución estatal, resulta primordial. En consonancia con este planteo, se analizan las representaciones que se evidencian en la sentencia del Tribunal Superior de Justicia de la Ciudad Autónoma de Buenos Aires (en adelante, el nombre de la ciudad se abreviará: CABA).

Por ello, si bien este inciso fue finalmente derogado por medios legislativos, no ha sido objetivo del presente artículo el análisis de dicha resolución, ya que el objeto de investigación lo constituyen las representaciones del poder judicial, específicamente las del Tribunal Superior de Justicia de la CABA. No obstante, puede decirse que “... las razones de los votos que conformaron la minoría devinieron en el debate ampliado las que justificaron la modificación de estatuto impugnado.” (CLÉRICO; SCHVARTZMAN, 2007, p. 368).

En suma, el caso ${ }^{2}$ a analizar en el presente artículo se trata de un pedido de declaración de inconstitucionalidad del artículo $1^{\circ}$ inciso “a” de la Ley 668, que establecía ser argentino como requisito para ingresar a la docencia en la CABA. El Gobierno de la Ciudad, al contestar la demanda, expone que los fines que persigue la normativa cuestionada, remite a que la tarea docente en el ámbito de la educación pública debe ser un lugar de transmisión de la identidad nacional, siendo los maestros argentinos los encargados de llevarla a cabo. Por este motivo, los extranjeros — en su calidad de nacidos fuera de la comunidad nacional — no serían idóneos. La Asociación por los Derechos Civiles $^{3}$ (ADC) lleva adelante un pedido de inconstitucionalidad del inciso de la ley, alegando que viola el "principio de igualdad ante la ley y el derecho a no ser discriminado por razones de nacionalidad". 4

En el caso se establece, como dice Bourdieu (2000, p. 185), un "conflicto reglado entre partes". En la sentencia ${ }^{5}$ se relatan cada una de las posiciones y se establece una disputa argumentativa entre los involucrados. La sentencia, cuyos tramos se analizarán en clave de representaciones sociales ${ }^{6}$, es la emitida por los jueces del Tribunal Superior de Justicia de la CABA. Son varias las subdimensiones sobre las que se indagará, pero que pueden resumirse en el análisis bajo la categoría de representaciones sobre el nacionalismo (entendiendo por tal la ideología del Estado nación) en sus dos versiones: culturalistas y constitucionalistas. Estas categorías de análisis han sido tomadas de Terán (2008, p. 121), quien define que “...el nacionalismo culturalista dice que ser argentino o lo que fuere es identificarse con un conjunto de pautas culturales (tales como la lengua, ciertos símbolos, usos y costumbres presentes y pasados, cierto «tipo nacional»)" mientras que el nacionalismo constitucionalista “... dice que la identidad nacional se define por pertenecer y adscribir a un mismo conjunto de 
leyes fundamentales...”, por ejemplo la Constitución Argentina. El análisis del caso procura visibilizar las marcas o "huellas históricas" (COHEN, 2009, p. 12) que aún persisten en los imaginarios actuales acerca de la identidad nacional argentina y su vinculación con las limitaciones al reconocimiento de los migrantes como sujetos titulares de derechos. En este sentido, al evidenciar, en los argumentos de los jueces, las representaciones sociales excluyentes, se pretende señalar la gravedad que este tipo de sentencias supone para el principio de progresividad en materia de derechos humanos.

Los argumentos de los jueces hacen referencia cada una de las dimensiones mencionadas anteriormente. Con fines expositivos, el artículo se estructura del siguiente modo. En primer lugar, se realizan algunas especificaciones teórico-metodológicas. Luego, a modo de contextualización, se presentan brevemente un mapeo de la jurisprudencia sobre derechos de los migrantes en Argentina y una mención a la legislación migratoria actual. A continuación, se analiza el contenido del fallo. Se empezará desglosando los fundamentos "nacional-culturalistas" y la relación entre la idoneidad para ejercer el cargo de docente de primaria y la pertenencia nacional para luego continuar con los argumentos vinculados al nacionalismo-constitucionalismo. Finalmente, se presentan algunas palabras de cierre.

\section{ESTRATEGIA TEÓRICO-METODOLÓGICA}

El análisis de este caso se desprende de una investigación de mayor envergadura, cuyo objetivo ha sido indagar acerca de las representaciones sociales y el desempeño institucional del sistema judicial del ámbito de la CABA con relación a los derechos humanos de los migrantes internacionales llegados a nuestro país a partir de la segunda mitad del siglo XX. Este caso se seleccionó por considerarse paradigmático, ya que, en la sentencia se hace referencia a un derecho fundamental, como lo es el derecho al trabajo, por su pretensión de generalidad, al tratarse de un pedido de inconstitucionalidad, y las representaciones sociales sobre los migrantes, en relación con la identidad nacional, lo que puede evidenciarse, dada la riqueza de los argumentos de los jueces que fallan. De este modo:

La selección del caso [no] se realiza por azar como en los métodos estadísticos, porque se parte de la no equivalencia entre los casos, que se destaca a través de la propuesta orientada a la comprensión de la especificidad de cada caso. El proceso de selección está basado en criterios teóricos, en experiencias de observación y en las expectativas depositadas en la unidad seleccionada, en términos de su potencialidad para proveer una base empírica relevante para la interpretación y comprensión del fenómeno estudiado. (ARCHENTI, 2007, p. 246) 
En términos generales, este caso se presenta en la jurisprudencia consultada sobre derechos de migrantes en el país, se cita en documentos y artículos de juristas y/o académicos y también se menciona en oportunidad de entrevistas realizadas a "informantes claves", a los que se ha consultado, por las características regresivas del fallo en cuanto al reconocimiento de derechos de los extranjeros. De esta manera, haciendo nuestras las palabras de Clérico y Schvartzman (2007, p. 345):

Cuando podíamos sostener que el acceso a la docencia pública y privada en el nivel básico y medio de los extranjeros residentes en el país formaba parte de un derecho amparado por la igualdad consagrada en la Constitución Nacional, irrumpe el fallo del Superior Tribunal de Justicia de la Ciudad de Buenos Aires sobre la constitucionalidad del Estatuto Docente Municipal que exige el requisito de nacionalidad argentina para el ingreso o reingreso a la docencia.

Asimismo, analizar un caso a través de sentencias adquiere relevancia porque en Argentina los juicios orales son escasos, lo que sitúa los fallos como entre los medios centrales por los cuales la comunidad jurídica se comunica entre sí y con la sociedad en su conjunto.

Para el análisis de la sentencia y de las representaciones sociales presentes en la misma, se realizó inicialmente una codificación abierta según la metodología de Strauss y Corbin (2002) para estimular el descubrimiento de categorías, propiedades y dimensiones de análisis. Luego, se utilizó el programa Atlas Ti, de modo de llevar a cabo una codificación selectiva en la búsqueda de un proceso de reducción de categorías, facilitando así el entrelazamiento de codificación-grillado, el análisis de contenido de los discursos y la interpretación de la información obtenida.

La hipótesis central, que subyace al análisis del caso, es que existe una representación social diferencial, entre los miembros del sistema judicial, acerca del reconocimiento y el acceso universal a los Derechos Humanos que migrantes internacionales, por un lado, y nativos, por el otro, deberían tener. La misma se sustenta en que se considera cuando menos pensable establecer algún tipo de distinción entre extranjeros y nacionales, contradiciéndose así los principios de universalidad e integrabilidad de los derechos humanos.

De esta hipótesis se desprenden las siguientes preguntas problema: ¿Cómo se vincula el sistema judicial con las poblaciones migrantes internacionales recientes? ¿Cuáles son las representaciones sociales sobre los migrantes que componen la mirada que el sistema judicial tiene sobre aquellos? Teniendo en cuenta esa mirada: ¿Cuál es el grado en que los derechos humanos de las personas migrantes son justiciables? ¿Cómo inciden en las garantías para el acceso real de los migrantes a la justicia? ¿Cuáles serían los obstáculos que dichas representaciones sociales pueden significar para 
que efectivamente se den esas garantías? ¿Qué rol le compete al sistema judicial? ¿Cómo se ve reflejado en las representaciones sociales de los miembros del poder judicial? ¿Y en su accionar? ¿Qué idea de igualdad y de derechos humanos persiste? ¿Cuáles son las contradicciones del sistema judicial, del propio Estado y del modo como está organizada la comunidad política estatal nacional, frente a la retórica de la universalidad de los derechos humanos?

\section{Algunas referencias a la jurisprudencia sobre Derechos de migrantes en Argentina}

Existen una serie de casos paradigmáticos sobre derechos de migrantes, tales como: Repetto, Calvo, Gottschau, Hooft y Reyes Aguilera. Estos casos, que forman parte de antecedentes importantes en materia de reconocimiento de derechos de extranjeros, llegaron a la Corte Suprema de Justicia, la cual entendió que las distinciones empleadas eran categorías sospechosas de discriminación. En estos casos se aplicó el "test de razonabilidad estricto" que supone que “...el fin de la medida (de distinción) sea legítimo e importante pero además imperioso" (DULITZKY, 2007, p. 20).

El primer antecedente es el fallo de "Repetto c/ Provincia de Buenos Aires", en el que se debatía la validez de una norma que establecía que se debía ser nacional para ejercer un cargo docente en un jardín privado. En los fundamentos del fallo se presume la inconstitucionalidad de la norma en virtud de lo establecido en el artículo 20 de la Constitución Nacional, que establece que los extranjeros gozan en el territorio de la Nación de todos los derechos del ciudadano. Luego, vendrían otros casos en los que también se discutía acerca de la igualdad entre nacionales y extranjeros. En el caso "Calvo y Pesini”, se cuestionaba una norma de la Provincia de Córdoba que exigía la nacionalidad argentina para un cargo de psicóloga en un hospital público. Dejando de lado el criterio de mera razonabilidad y aplicando el más estricto, la justicia decidió que el Estado no había logrado fundamentar fuertemente las razones para la distinción, declarándose la norma como inconstitucional. En el caso "Hooft" también se aplicó el test y se declaró inconstitucional el artículo 177 de la Constitución de la Provincia de Buenos Aires, que exigía ser argentino o hijo de argentino para acceder al cargo de juez de cámara. También vinculado a un cargo judicial (en este caso, secretario de Primera Instancia) se requería la nacionalidad argentina. Retomando el test aplicado en Hooft, la Corte Suprema exigió al Estado que justificara rigurosamente los motivos de la distinción. Los estándares de estos dos últimos casos fueron aplicados luego al caso "Mantecón Valdés", en el que se discutía la distinción de nacional como criterio para concursar al cargo de auxiliar en la Biblioteca de la Corte Suprema de la Nación. Finalmente, en el caso Reyes Aguilera, en el que una niña de nacionalidad boliviana solicitaba una pensión por invalidez, dos de los jueces dictaminaron la inconstitucionalidad de la norma en cuestión, 
aplicaron un criterio estricto de igualdad e invirtieron el cargo de la prueba hacia el Estado. ${ }^{7}$

De este modo, estos casos fueron marcando una tendencia hacia una mayor exigencia y fundamentación respecto a los motivos para el establecimiento de distinciones entre extranjeros y nacionales en normas como las reseñadas. Es así, que Clérico, Ronconi y Aldao sostienen que se viene produciendo un cambio de paradigma (en el que la nacionalidad es un criterio de clasificación prohibido y que implica la aplicación de un examen estricto de igualdad) que “... ha permitido reconocer derechos principalmente a aquellas personas que no solo padecen una discriminación por la nacionalidad sino también, principalmente, a los migrantes y otros grupos que padecen una situación de desventaja estructural” (CLÉRICO, RONCONI y ALDAO, 2013, p. 128). En el marco de esta tendencia, el resultado del caso aquí presentado se aleja de aquellos precedentes.

Por otro lado, a modo de contextualización, debe decirse que, en Argentina, desde la reforma de la Constitución de 1994, se han reconocido una serie de derechos humanos y se han incorporado un cúmulo de tratados internacionales al texto normativo. Sin embargo, esta "constitucionalización de los derechos" ha sido paralela a un proceso de deterioro en el cumplimiento de los mismos, producto del desmantelamiento, por la vía legislativa, de prestaciones sociales universales y otros derechos laborales que históricamente habían sido reconocidos en nuestro país. Este doble proceso, de carácter esquizofrénico, generó un escenario en el que las leyes reconocían de manera progresiva y universal todos los derechos humanos, al tiempo que su incumplimiento se volvía casi una política de Estado. Frente a esta situación se instaló el concepto de “judicialización de la política social”, que se refería a una creciente participación por parte del sistema judicial —dado que ciertos sujetos y grupos comenzaron a tomar el recurso judicial como una herramienta más para la defensa de sus derechos- en la resolución de casos sobre derechos económicos, sociales y culturales (ABRAMOVICH; PAUTASSI, 2009, p. II). Así, hacia los años 80 y, fundamentalmente, en los 90, este tipo de "soluciones" a través del sistema judicial, comienza a proliferar.

Teniendo en consideración este rol central del poder judicial y que la aplicación de un criterio de igualdad más o menos exigente en relación con los extranjeros, como también la consideración acerca de si el legislador o el Estado logra presentar razones imperativas para que la distinción aplicada sea o no constitucional, siguen siendo decisiones de los magistrados, nuevamente, adquiere importancia el análisis del presente caso, desde una perspectiva que incluya las representaciones sociales de los miembros del sistema judicial. En tanto la sentencia va a contramarcha de los precedentes reseñados más arriba, suponiendo un retroceso en la consecución de construir una sociedad que incluya a los extranjeros en condiciones de igualdad con los nativos, indagar acerca de los argumentos de este tipo de planteamientos resulta imperativo para que el criterio de universalidad de los derechos humanos no quede reducido a una simple declaración de intenciones. 


\section{LA INSTITUCIÓN ESCOLAR Y LA FUNCIÓN DE TRANSMISIÓN DE LA "CULTURA NACIONAL"}

Cinco son los jueces que fallan en el caso. Dos de ellos lo hacen a favor del pedido de inconstitucionalidad del inciso y tres en contra del mismo. Los primeros afirman que las razones de la distinción son discriminatorias y que el Estado no logra argumentar por qué resulta necesaria la misma a los efectos de que se cumpla un "fin estatal imperioso". Cuando se aplica este criterio estricto de igualdad, es el Estado el que debe probar que el empleo de la clasificación sospechosa es estrictamente necesario para el cumplimiento de un fin legítimo. No es suficiente, entonces, con señalar la licitud del fin a alcanzar, sino que el Estado debe justificar por qué era necesario acudir a una distinción fundada en una clasificación sospechosa para cumplir esos fines. Así, desde la perspectiva de los jueces que fallan a favor de declarar inconstitucional el inciso de la norma, el argumento de la necesidad de ser argentino no puede sostenerse.

a) la actora ha demostrado cabalmente el empleo por parte de la legislación local de una de las "clasificaciones sospechosas" señaladas por el art. 11 de la Constitución de la Ciudad de Buenos Aires [en adelante: CCBA], en el caso, la nacionalidad;

b) el Estado, a su turno, no ha logrado justificar la necesidad del empleo de esta clasificación para efectuar una distinción de trato que, en este caso, excluye a un grupo de personas — los extranjeros — de la posibilidad de ingresar o reingresar a la docencia, excepto i) en el área de educación superior y ii) en el supuesto de que "razones de idoneidad así lo requieran, debiéndose fundamentar tal circunstancia en el acto de designación” (ley $\mathrm{n}^{\circ} 668$, art $1^{\circ}$ ) en cuyo caso el aspirante deberá acreditar otros cuatro extremos —aquí no reproducidos_- exigidos por la norma en crisis; c) las razones alegadas por el Estado, excesivamente genéricas a veces, implausibles otras (que, incluso, agravan el carácter arbitrariamente discriminatorio de la norma impugnada), no logran demostrar que la distinción resulte necesaria, tan siquiera adecuada, para alcanzar un fin legítimo. Vagamente se esgrimen razones vinculadas con una supuesta “incapacidad de absorción de elementos axiológicos" por parte de los extranjeros, los cuales hacen a una idiosincrasia nacional, transmitida sólo por quienes están imbuidos de tales elementos telúricos, imprescindibles para enseñar, por caso, un teorema matemático. ¿Cuál es la relación entre estas especulaciones, que contrarían al menos tres normas constitucionales de nuestro país e incontables disposiciones internacionales que obligan a nuestro Estado, por un lado, y la exigencia de idoneidad pedagógica, que debería ser el tema excluyente de debate entre la actora y el Gobierno local, por otro? 
De igual modo, el propio régimen jurídico de la función docente descalifica el empleo del supuesto "argumento de la idiosincrasia". En efecto, de acuerdo con el régimen vigente, las funciones para las cuales se les impide concursar a los extranjeros para cargos en la crucial función docente, por considerárselos, por así decir, "biográficamente inhábiles”, son ejecutadas por personas que concursaron, claro está, sin tener que dar cuenta de su sostenida convicción íntima en tanto "ser argentino" ... puede advertirse claramente que el argumento de la necesidad de ser argentino ni siquiera puede sostenerse a la luz del régimen jurídico vigente. [...].

Esta pretendida fundamentación no sólo es pobre y confusa, sino que, al igual que el texto de la norma impugnada, resulta (como destaca la parte actora a fs. 26), "una típica generalización esteriotipada (sic) y discriminatoria de los extranjeros, en tanto se les atribuye en forma genérica y especulativa, la capacidad de 'contaminar' las mentes de los alumnos de las áreas de educación distintas a (sic) la superior, lo cual resulta claramente inadmisible a la luz de la jurisprudencia reseñada” (fs. 26). (Párrafos de la sentencia Asociación por los Derechos Civiles (ADC) vs. Gobierno de la Ciudad de Buenos Aires s/ acción declarativa de inconstitucionalidad del 31 de marzo de 2005. En adelante ADC vs. GCBA)

En suma, en el caso de las juezas que evaluaron que el pedido de inconstitucionalidad era acertado, los argumentos para fundamentar el fallo remitían a considerar sospechosas las normas que clasifican y definen la idoneidad para el cargo en función de la nacionalidad de la persona. Así, estas juezas recurren, entre sus fundamentos centrales, a la prohibición de distinción que establecen los artículos 16 y 20 de la Constitución Nacional y 11 de la Constitución de la Ciudad de Buenos Aires para él, así como la no exigencia de adquirir la ciudadanía. Asimismo, una de ellas toma del Derecho Internacional la prohibición de discriminación por nacionalidad. La otra jueza que conforma la minoría fundamenta la presunción de categoría sospechosa, fundamentalmente, a partir de que el Estado no logra demostrar que la distinción para el ingreso a la docencia por nacionalidad estuviera justificada. De este modo, plantea que los motivos por los cuales se considera que los extranjeros no son idóneos para el cargo poseen un nivel de abstracción que los convierte en inadmisibles y absurdos:

Lo que no puede dejar de advertirse es la autocontradicción en que se incurre cuando son expuestos — según le corresponde por obligación al GCBA - los propósitos “de interés superlativo” por los que la norma en crisis discrimina a los extranjeros en la materia que la ley $\mathrm{n}^{\circ} 668$ procura regular. En efecto, no se requiere demasiado para advertir el hiato en el razonamiento que se configura si se afirma, por un lado, que "resulta 
irrazonable e intrusivo exigir un comportamiento enraizado en las convicciones más íntimas del ser humano a quien por no ser argentino, habilita palmariamente una presunción en contra de la posesión de las mismas en su carácter de foráneo” y, por otro, que tal imposibilidad empírica de verse dotado de tales "íntimas convicciones” puede ser rápidamente subsanada, por un trámite absolutamente burocrático, merced a la decisión de naturalizarse argentino/a, procedimiento que, además, comporta "un trámite sencillo". Todas estas aseveraciones, su carácter contradictorio y hasta absurdo en el intento de ocultar motivaciones discriminatorias que se presumen a menos que se brinden las plausibles explicaciones del caso... (Párrafo de la sentencia ADC vs. GCBA)

De este modo, se hizo alusión a lo inconsistentes que resultaban los argumentos, que remitían a la defensa de la identidad nacional, la idiosincrasia y los valores nacionales del Estado, para negar el acceso a un cargo docente en las escuelas públicas. Al contrario, se advertirá cómo esos mismos argumentos sí resultaron razonables para los jueces que fallaron a favor de la constitucionalidad del inciso de la ley en cuestión.

Asimismo, desde la postura minoritaria se rechaza todo elemento vinculado a la idiosincrasia o a una visión esencialista de la identidad que inhabilitaría a los docentes extranjeros a ejercer un cargo de maestro de primaria. Del mismo modo, si bien se recurre a la Constitución Nacional y los artículos que reconocen la igualdad entre nativos y extranjeros, son mencionados por una de las jueces también normativas internacionales. Estos pactos y tratados de carácter internacional son los incorporados en el reforma de 1994.

Por otra parte, en los fundamentos de los jueces (la mayoría) que sostienen la constitucionalidad del inciso de la norma, pueden evidenciarse argumentos del tipo de "nacionalismo culturalista". El análisis de esta sentencia permite ver el ideario y las funciones que en parte del sistema judicial se le atribuyen a la escuela como institución estatal y su relación con la presencia de migrantes. Históricamente, la institución escolar ha cumplido un rol fundamental en el proceso de constitución de la identidad nacional. Los docentes llevarían adelante en la escuela pública normal la "misión nacionalizadora”, ya que allí confluirían los niños de las más diversas extracciones sociales. Ya fuesen nativos, migrantes, nativos hijos de migrantes o de nativos, se "encontrarían" a los efectos de aprender a leer y escribir, adquirir conocimientos de las diversas ciencias, pero también valores, imaginarios, un sentimiento de pertenencia nacional, de patriotismo, de semejanza. Se trataría de homogeneizar a una población, de normalizar a una masa de futuros ciudadanos. Este rol, que se le encomienda a los docentes en la época de la formación de los Estados nacionales, iría acompañado por un imaginario acerca de cómo debería ser ese docente. Muchos de los elementos de ese imaginario parecieran persistir en lo dicho por los jueces en esta 
causa, ya que asocian la idoneidad con la capacidad de los docentes de transmitir los "ideales nacionales".

El Estado considera que los niños que se encuentran en determinada edad escolar y concurren a las escuelas públicas deben formarse con maestros que deben reunir, entre otros requisitos de idoneidad, el de la nacionalidad argentina. ¿Por qué? La misma ordenanza lo explicita en su art. $6^{\circ}$, inc. b). En este punto, también cabe mencionar lo expresado hace más de un siglo por el prestigioso publicista ya citado cuando dijo: "En toda nación libre la escuela debe realizar estos tres conceptos: crear su cultura humana, encaminarla a fortalecer y perpetuar la nacionalidad, y hacer al pueblo capaz de gobernarse por sí mismo y realizar con verdad los propósitos generales y especiales de la Constitución. (Joaquín vs. González, p. 175 en Párrafo de la sentencia ADC vs. GCBA)

A razón de estas referencias al pasado, se hará un breve paréntesis para mencionar algunos procesos que definieron la conformación de la escuela como institución en Argentina y que resuenan aun hoy en la misma.

Bertoni (2007, p. 43) plantea que la “cuestión nacional” no era la preocupación inicial en las escuelas, sino que ella iría apareciendo gradualmente. A fines de 1870 y comienzo de 1880 urgía con mayor apremio resolver la cuestión de cómo enseñar sin contar con la cantidad necesaria de maestros facultados ni la capacidad edilicia requerida. Esos fueron los primeros objetivos del Estado en relación con la educación. Recién hacia 1887 se percibe un “...movimiento renovador en el Colegio Nacional de Educación, que coincide con el auge de la preocupación por la nacionalidad y la manifestación del entusiasmo patriótico" (BERTONI, 2007, p. 45). Esta referencia a la preocupación, en general, por la nacionalidad es una muestra de cómo la escuela, en tanto institución, no puede ser vista por fuera del Estado y del campo social en general. Así, la escuela refleja los acontecimientos sociales y objetivos del estado nacional. En vistas de este «propósito nacionalizador» “... se destacaron los contenidos nacionales en los nuevos planes y programas y se estableció la selección y autorización periódica de los libros de texto; se otorgó mayor importancia a la enseñanza de la historia patria y a la realización de actos escolares, y se procuró que la actividades escolares trascendieran hacia la sociedad en ocasión de las fiestas patrias" (BERTONI, 2007, p. 45). Continuaban siendo, para ese momento, problemas centrales la escasez de maestros bien formados, la reducida matrícula y el ausentismo de los estudiantes. Era necesaria la presencia de los niños en las escuelas para generar el sentimiento de pertenencia a la patria. A ello se sumaba la existencia de las escuelas de extranjeros (de italianos, españoles, alemanes), en las que se inculcaba el sentimiento hacia otro terruño y que competían con la "escuelas comunes", 
como se las llamaba. Así, el objetivo principal sería crear un sistema que estuviera regido por lo dictaminado por el Estado nacional.

Ya hacia los años finales del siglo XIX podía leerse, en la declaración del director de la Escuela Normal de Profesores de Buenos Aires, la advertencia a los maestros acerca de que el alumno "vendrá, en una palabra, con la cabeza, con el corazón y hasta con el estómago italiano” y la escuela debía ser, por ello, el lugar donde se despertara el sentimiento patriótico, "en la República Argentina, más que en cualquier país de la tierra, la educación debe tener un propósito nacional” (BERTONI, 2007, p. 119).

En suma, se trataba de "moldear" las personalidades de los niños, "contaminados" por los idiomas, costumbres y sentimientos patrióticos que aprendían en sus hogares. De modo tal, que no serán solo contenidos conceptuales y destrezas las que se impartirían sino también valores nacionales, cuasi morales. Como plantea Feldfeber (1996, p. 8): "La educación moral se convertiría en el objetivo principal de la escuela públi$\mathrm{ca}$, junto a los ramos instrumentales y aquellos conocimientos mínimos que acrediten a cada individuo como 'ciudadano' de la Nación”.

Retomando ahora el análisis del fallo, en vinculación con la dimensión que asocia idoneidad e identidad nacional, puede verse que se realza la importancia que la escuela cumple en la conformación del sentimiento nacional y el interés que en el mismo tiene el Estado. En ese objetivo los docentes son los principales transmisores de contenidos vinculados a la recreación del sentir nacional.

Que los docentes del 'preprimario' y 'primario' trabajan sobre una circunstancia humana particularmente sensible, y que sus personalidades (no sus meras apariencias) se convierten en modelos de identificación de los niños y los estampan significativamente en su futuro comportamiento social... También es verdad que el Estado tiene en la educación un interés vital. (Párrafo de la sentencia ADC vs. GCBA)

...en buena parte de sus supuestos, el de los maestros de escuela primaria, el docente es un conductor único de la enseñanza en el grado, de manera que si la nacionalidad es significativa para la transmisión del mensaje, naturalmente es también justificado que sea ella exigida al único transmisor: el maestro. En el caso de los docentes del área de Educación Superior, la situación es algo menos intensa. Mientras el compromiso que la ciudadanía implica puede estimarse relacionado con la enseñanza de la historia, es difícil verlo en el supuesto de la de matemáticas. Sin embargo, es admisible que el legislador vea en todo educador, en mayor o menor grado, un líder espiritual... (Párrafo de la sentencia ADC vs. GCBA) 
Las instituciones estatales son las encargadas de crear y reactualizar continuamente el "compromiso con la comunidad nacional" de todos sus miembros (BALIBAR, 1991, p. 152; 2005, p. 61). Para lograr su eficacia ese relato histórico recreado debe ser además invisible. En esa labor los docentes y la escuela cumplen un rol fundamental, ya que allí los docentes imponen una "visión del mundo" que aparece como natural. La idea de Nación se ancla en una doble ilusión: de proyecto y de destino (BALIBAR, 1991, p. 136) que comparten los miembros de la comunidad nacional. Pero para la generación de esta identidad, que es transindividual, es preciso un proceso de identificación. Allí es cuando la escuela actúa como regeneradora de sentimientos tales como; el patriotismo, la idea de una "etnicidad ficticia", de valores comunes compartidos "desde siempre": "...toda comunidad social, reproducida mediante el funcionamiento de instituciones, es imaginaria, es decir reposa sobre la proyección de la existencia individual en la trama de una relato colectivo, en el reconocimiento de un nombre común y en las tradiciones vividas como restos de un pasado inmemorial [...]”. Esto viene a significar que sólo las comunidades imaginarias son reales, cuando se dan determinadas condiciones" (BALIBAR, 1991, p. 145). En suma, en este proceso transindividual de creación de identidad, las instituciones (escuela, justicia, ejército, etc.) reducen la multiplicidad y complejidad de identidades, jerarquizándolas y colocando a la identidad nacional como una de las principales.

El requisito de la nacionalidad, por sí solo, no convierte a una persona en idónea para cumplir con los deberes que las leyes de educación le imponen - aptitudes que deberán ser apreciadas, en cada caso, por la autoridad administrativa correspondiente-, pero sí permite suponer, en ese individuo que posee la nacionalidad, un mayor compromiso con la comunidad que lo recibe. Es por ello que resulta razonable el requisito de nacionalidad establecido en la normativa en cuestión. (Párrafo de la sentencia ADC vs. GCBA)

... Es a todas luces evidente que quien es habitante de la Nación, pero no adopta la nacionalidad argentina no obstante tener abierta esa posibilidad, está en una situación en que le resulta difícil ser convincente en la tarea de inducir el compromiso del alumno con la sociedad argentina. Ello no significa forzar al habitante extranjero a naturalizarse, ni por imperio de la ley ni de la presión económica, puesto que tiene muchos modos de ejercer su profesión sin acudir al empleo público. La categoría con que el legislador ha buscado distinguir entre quienes tienen el compromiso con la idea transmitida y quienes no lo tienen es una categoría que recorta estrictamente el universo de quienes pueden predicar con el ejemplo. (Párrafo de la sentencia ADC vs. GCBA)

De esta manera, solo los miembros de la comunidad nacional pueden "predicar con el ejemplo". La idea de pertenencia rememora a lo dicho por Anderson (2002, p. 23) 
en relación a la cuestión de la Nación y a los mecanismos de creación y recreación de la comunidad nacional. Entre sus ideas fundamentales se encuentran que la nación y/o el nacionalismo son "artefactos culturales" de una clase particular creados a fines del siglo XVIII y define a la Nación como “... una comunidad política imaginada como inherentemente limitada y soberana. Es imaginada porque en la mente de cada uno vive la imagen de la comunión”, aunque nunca lleguen a conocerse entre sí cada uno de sus miembros. Es limitada porque tienen fronteras finitas, aunque elásticas: “...ninguna Nación se imagina con las dimensiones de la humanidad”. Es soberana porque se basa en un Estado Soberano nacido en la época en que la Revolución Ilustrada que echó por tierra la legitimidad del "reino dinástico jerárquico divinamente ordenado". Es una comunidad porque se concibe como un "compañerismo profundo, horizontal” más allá, y a pesar, de las desigualdades que pudieran existir.

Es decir, en cuanto comunidad limitada resulta inclusiva pero también excluyente. A ello se refiere Terrén (2003, p. 134) cuando postula la paradoja de la notridad, de Alexander, para explicar la producción de solidaridad social de un grupo determinado. De manera que la imagen de Nación habilita la delimitación de fronteras, no solo materiales, sino también simbólicas (BALIBAR, 2005, p. 77-86). En este caso, el docente extranjero representa aquel que no porta los valores que deberían transmitirse a los futuros ciudadanos de la Nación. Encarna al forastero de Schütz, aquel ser que posee pautas culturales (usos y costumbres, leyes, hábitos, modas) diferentes a las de la sociedad receptora.

¿Cómo puede mesurarse el compromiso con los valores nacionales? Más aún: ¿Cuáles serían esos valores nacionales que deberían transmitirse y protegerse de una eventual contaminación exógena de docentes extranjeros? Puede decirse que una visión estática de la identidad nacional atraviesa estas ideas. Esta mirada supone una doble ilusión: de proyecto y de destino. Que se basa en creer que, de generación en generación, se transmite una especie de sustancia o sustrato invariable y en la creencia que esa evolución que compartimos es la única que podría acontecer (BALIBAR, 1991, p. 135).

La extranjeridad ${ }^{8}$ del docente migrante estaría dada por conservar formas de pensar y de actuar esencialmente diferentes a las "nuestras". Dicho docente posee otro esquema de pensamiento para manejarse en el "mundo de la vida", en la cotidianeidad. Ahora bien, como se ha planteado anteriormente, el modo como los nativos nos representamos a los "otros" extranjeros, es decir, nuestras representaciones sociales, si bien suponen la clasificación y clasificación, no siempre debe ser excluyente. Ello sucede cuando opera además un proceso de jerarquización. Esta jerarquización puede o no ser más evidente o puede enmascararse bajo un "multiculturalismo tolerante". En este último caso, no se niega que puedan existir otras pautas culturales que deban respetarse; pero lo mejor sería que se manifestaran solo en un espacio privado, como los hogares de cada extranjero, o incluso en escuelas privadas, pero no en las estatales. De este modo, “...la tolerancia no incluye la aceptación del valor del otro; por el contrario, es, 
una vez más, aunque de manera más sutil y subterránea, la forma de reafirmar la inferioridad del otro" (BAUMAN, 1996, p. 82).

[...] El Gobierno de la Ciudad, al contestar la demanda, ha expuesto los fines que persigue la normativa cuestionada, en síntesis, que la tarea docente en el ámbito de la educación pública "sea desempeñada por agentes educadores que resulten portadores naturales del sistema de valores, de la visión del mundo, de la condición de identidad cultural e histórica que es particularmente propia de nuestro país y que puede no serlo de otro", y destacado la importancia que tiene para ese Gobierno "...el proceso de socialización primaria, durante el cual el individuo conforma su identidad”. Señaló también las características de la sociedad postmoderna multicultural, multirracial y multiétnica, propias del mundo globalizado, en el que las identidades de los extranjeros ya no se funden con las del país receptor sino que se mantienen en forma claramente diferenciada”. (Párrafo de la sentencia ADC vs. GCBA)

De este modo, en la época multicultural no puede aplicarse el "exitoso" proceso de asimilación, que describimos anteriormente, propio del proceso de conformación de Estado Nacional Argentino. Ahora, el respeto por la diferencia y la particularidad del "otro" se presenta como un valor central de las sociedades plurales en las que vivimos. Al mismo tiempo, para el multiculturalismo, los extranjeros parecen ser más "obstinados” en mantener sus costumbres y prácticas culturales. Es por ello que, como sostienen diversos críticos del multiculturalismo, la tolerancia multicultural resulta ser uno de los discursos más convenientes para el orden económico y político de nuestro tiempo, ya que, al tiempo que respeta a los "otros" con sus singularidades culturales, ello permite también dos procesos complementarios de no-vinculación con el "otro": por un lado, mantenerlo a distancia, posibilitando que pueda desplegar sus atributos, costumbres y valores esencialmente diferentes y, por otro lado, no incluir en la ecuación las reivindicaciones económicas y políticas de los colectivos que conforman esa alteridad apreciada como tangencialmente disímil a "nosotros" (ZIZEK, 2008, p. 56; DÍAZ POLANCO, 2006, p. 173).

En esta misma línea, autores como Zizek problematizan categorías que suelen resonar tanto en ambientes académicos, escuelas, plataformas políticas, etc., cuando se intenta hablar de las relaciones y las condiciones en que nos vinculamos con los "otros", tales como: "tolerancia" y "respeto". Zizek (2008, p. 60), en su libro En defensa de la intolerancia, y en sintonía con su conceptualización del multiculturalismo liberal, sostiene que en este se tolera la otredad mientras la misma no suponga el establecimiento de relaciones reales con el otro. En ese momento la mirada tolerante se acaba. En términos concretos, cuando el extranjero quiere acceder a un puesto laboral, reservado por ley —en tanto imposición soberana estatal—a los nativos, es 
cuando la tolerancia encuentra su límite. En ese intento por excluir al migrante se considera valorable la "cultura" del aquel, pero no para su transmisión en los espacios escolares. De este modo, el "generoso" Estado — en tanto polo dominantedetermina quién es incluido y quién es excluido.

[...] tanto la Ciudad de Buenos Aires ha entendido, anticipadamente a la concreción constitucional explícita del ideario argentino en educación, que la enseñanza pública debe comprometerse en brindar a los hijos de sus vecinos una formación, a partir de recursos docentes idóneos por su nacionalidad argentina, que priorice la unidad nacional, que tienda a proteger la identidad y pluralidad cultural, que se ocupe de reconocer la preexistencia étnica y cultural de los pueblos indígenas y que, asimismo, tome a su cargo promover los valores democráticos (art. 75, incs. 17, primer párrafo, y 19, tercero y cuarto párrafo de la Ley Suprema). (Párrafo de la sentencia ADC vs. GCBA)

Asimismo, esta manera de concebirse la diversidad implica que los discursos negativos acerca de "lo otro" también sean menos burdos y abiertos y que se recurra a la idea de la negociación entre las partes para lograr un pacto acordado. En sí misma, esta posición no sería criticable si se tuviera en cuenta que "las partes", que participan de ese diálogo suelen estar situadas en diferentes y desiguales lugares. Consecuentemente, la posibilidad de que el resultado de la negociación sea a favor de una parte o de la otra, dependerá de la fortaleza y de los capitales (económicos, simbólicos y sociales) de cada uno de los involucrados. En el caso de los migrantes internacionales y el Estado, es evidente que quien posee el mayor grado de fuerza es este último. En este sentido, es el Estado el que decide qué tolerar, o en el ejemplo aquí trabajado, quiénes pueden ocupar los cargos, diferenciando en públicos y estatales, de nivel primario, medio y universitario, qué prueba de "lealtad" se le requerirá al extranjero que quiera acceder a determinado puesto docente, etc. La asimetría de poder es evidente, así como su arbitrariedad, la cual se hace más clara cuando el extranjero se convierte casi "mágicamente" en idóneo para trasmitir los valores patrios y el sentimiento nacional al cumplir con el trámite de nacionalización, otro acto generoso, claro está, por parte del Estado para con el migrante, que le permite pasar por esa prueba de lealtad si pretende acceder a cumplir con la misión de transmisión de la identidad nacional. La cuestión de la nacionalidad (garante del compromiso) podría resolverse entonces con un trámite burocrático que compruebe el compromiso con la comunidad nacional, una especie de "rito de pasaje" a través del cual afirmaría el interés genuino del migrante en formar parte de "nosotros", de nuestra comunidad de "iguales".

Las reflexiones precedentes, en un país decididamente generoso para otorgar a los extranjeros la naturalización con la corta residencia de dos 
años continuos en el país - tal cual lo contempla y garantiza el art. 20 de la Constitución Nacional_- convierten el requisito de la nacionalidad para la docencia oficial en algo diferente a un indebido o exorbitante privilegio para los naturales del país. No es, por lo demás, una odiosa o inequitativa discriminación con finalidad persecutoria para con los extranjeros en general, o para con una nacionalidad en particular, extranjeros a quienes, además de la posibilidad de la naturalización, se les reconocen con amplitud el derecho a trabajar y ejercer industrias lícitas, incluso la docencia en establecimientos privados. (Párrafo de la sentencia ADC vs. GCBA)

Como se ha planteado, a fines del siglo XIX, la insistencia en la importancia de delimitar las fronteras geográficas iría acompañada por un proceso de nacionalización de la sociedad. Actualmente, los procesos de globalización están acompañados por otros discursos, también mencionados, que refieren al carácter cada vez más multicultural de las sociedades. Coincidiendo con lo que se sostiene en este tramo de los fundamentos de la sentencia, la globalización de capitales implicó un proceso de colonización en misma escala (ZIZEK, 2008, p. 55-56). En ese proceso se acepta con mayor displicencia la movilidad de los capitales que de las personas.

El pensamiento idealista que expresa la frase de Sócrates que refiere al hombre como ciudadano del mundo fue perdiendo el sentido altruista primigenio, constatable por la mundialización o globalización de la posmodernidad que, descarnadamente, ha entrañado la pretensión de una dominación universal por algunos países que la proyectan en lo político, económico y cultural, bajo la disuasión de su indiscutible poderío financiero y bélico". (Párrafo de la sentencia ADC vs. GCBA)

No obstante, esta consideración acerca de las consecuencias que el proceso de globalización — ciertamente deshumanizante - ha tenido no implica, necesariamente, que el mejor modo de contrarrestarlo sea la exacerbación del nacionalismo. Para que el migrante internacional se constituya en ese "otro" cultural y moralmente diferente, al que puede excluirse — por ejemplo, de un derecho laboral_ debe llevarse a cabo un proceso de esencialización de las diferencias. Ese momento esencializante “... es débil porque naturaliza y deshistoriza la diferencia, y confunde lo que es histórico y cultural con lo que es natural, biológico y genético. [...] siempre que naturalizamos categorías históricas fijamos ese significado fuera de la historia, fuera del cambio, fuera de la intervención política” (HALL, 2003, s/p).

En suma, por los elementos que se han podido analizar en esta sentencia, el asunto sobre el que se trata (derechos de los migrantes al trabajo) y los argumentos ligados 
a la nacionalidad como sinónimo de idoneidad, en la institución judicial, pareciera manifestarse una perspectiva sobre la globalización en la que

... en general, se acepta la idea de que en la época contemporánea de globalización económica, el Estado se ha desligado del concepto de economía nacional. [...] Sin embargo, la concepción del Estado Nacional sigue asociándose a la noción de una cultura homogénea única representativa de un pueblo específico, uniforme tanto en identidad como en historia. (STAVENHAGEN, 1994, p. 11)

Siguiendo con Stavenhagen, puede decirse que la Nación sigue siendo un referente central en la constitución identitaria, aunque a nivel de la economía mundial algunos Estados vean debilitado su accionar. Dicha persistencia identitaria se ve reforzada frente a la vulnerabilidad económica, lo que robustece la "notridad" al tiempo que refuerza las fronteras — simbólicas y materiales — con los "otros". En este sentido es que los capitales financieros son mucho mejor recibidos por las sociedades receptoras que los sujetos que migran. Al respecto, teniendo en cuenta lo dicho respecto a los procesos de fragmentación económica y social que atravesaron a la sociedad argentina, con niveles mayores o menores de exacerbación, los migrantes han cumplido el rol de "chivos emisarios". Así, aunque este tipo de discurso excluyente se presente más o menos virulento a lo largo de la historia argentina, el mismo se mantiene latente, pudiendo resurgir dependiendo de los avatares políticos y, fundamentalmente, económicos. Frente a este tipo de coyunturas, el recurso del "chivo expiatorio", encarnado en los extranjeros, y la necesidad imperiosa de fortalecer "nuestra” identidad nacional reaparecen y se aúnan en un solo discurso.

Así, los comunes denominadores que permitieron hablar de una patria humana universal, se ven desmentidos en el campo de la realidad concreta lo que obliga a una Argentina postergada a reafirmar y defender su identidad, valiéndose del instrumento poderoso de la educación y reivindicando los valores del patriotismo. (Párrafo de la sentencia ADC vs. GCBA)

Sociedades que, cada vez, pueden negar menos la existencia de diferencias; pero que, por medio de mecanismos de discriminación, señalamiento y demarcaciones, unos más sutiles que otros, profundizan procesos de exclusión en un mundo que retóricamente se presenta más tolerante e intercomunicado que nunca. Al mismo tiempo, las fronteras nacionales se manifiestan cotidianamente, en algunos países, con leyes de extranjería más restrictivas y, en casi todos, incluyen procesos cotidianos (a partir de normas, pero también de acciones, actitudes y prácticas reproducidas en diversos 
ámbitos sociales) de establecimiento de fronteras materiales y simbólicas, basadas en la pertenencia nacional. Al respecto, puede leerse en la sentencia:

El requisito de la nacionalidad argentina para quienes desempeñen la docencia en el ámbito público de la Ciudad de Buenos Aires encuentra su fundamento en razones que la Legislatura ha valorado como positivas dentro de la política de educación que le toca diseñar [...] Entre estos fundamentos, puede señalarse la transmisión de: la tradición cultural, los valores inherentes al concepto de Nación y de democracia, las formas de concientizar la pertenencia a la comunidad argentina, los conceptos patrios, de justicia y de respeto por los derechos humanos, entre otros (art. 6ºrdenanza 40.593). (Párrafo de la sentencia ADC vs. GCBA)

Entre esos ámbitos que trabajan en el proceso de elaboración de fronteras simbólicas se encuentran las instituciones. Así, la institución escolar funciona hasta el día de hoy, como maquinaria creadora de ciudadanos nacionales, por medio del ejercicio de la violencia simbólica sobre el conjunto de las sucesivas generaciones, confirmándose que "[...] uno de los poderes mayores del Estado es el de producir y de imponer (principalmente por medio de la escuela) las categorías de pensamiento que aplicamos espontáneamente a cualquier cosa del mundo” (BOURDIEU, 2002, p. 1).

Hasta aquí los fundamentos que se enmarcan dentro de un "nacionalismo culturalista”. Sin embargo, también es posible encontrar en la sentencia puntos que remiten a un "nacionalismo constitucionalista".

\section{Alberdi, el inspirador de la Constitución Nacional Argentina}

Como se ha analizado, el nacionalismo culturalista (más cercano a los fundamentos que refieren a la centralidad de la escuela como transmisora de la identidad nacional) supone la identificación con una serie de pautas culturales como la lengua, los símbolos patrios, costumbres, etc. En cambio, el nacionalismo constitucionalista e imitativo postula que "...la pertenencia a una nación se define por la adhesión a la Constitución de un país en tanto código que establece las leyes fundamentales que regulan aquellos derechos naturales y por ende universales: libertad, propiedad, seguridad, etc" (TERÁN, 2008, p. 104).

Se considera a Juan Bautista Alberdi como un miembro destacado de lo que se denominó, en la historiografía argentina, la “Generación del 37”. Dicho movimiento intelectual, cuya influencia se desarrollará desde 1837 hasta aproximadamente 1880 , enfatizaba la necesidad de construir una identidad nacional. Sus integrantes fueron Esteban Echeverría, Domingo Faustino Sarmiento, Juan María Gutiérrez, Vicente Fidel López, José Mármol, Félix Frías y, por supuesto, Juan Bautista Alberdi (TERÁN, 2008, 
p. 61). Las obras fundamentales de éste último son: Acción de la Europa en América, de 1842, y Bases y Puntos de Partida para la organización política de la República Argentina, de 1852. Según Terán, ambos nacionalismos pueden encontrarse en los discursos de la época de construcción de la Nación Argentina y Alberdi (citado recurrentemente en la sentencia) sería uno de sus representantes fundamentales. En la definición de Nación de Alberdi — en cuyas ideas y pensamientos se basa la Constitución Nacional Argentina - , no hay referencia a la idiosincrasia, no hay una preocupación por la contaminación de los valores nacionales por parte de los extranjeros. Al contrario, su propuesta inicial se orientaba al "transplante inmigratorio", que permitiría, luego de la mezcla con lo autóctono, la "mejora” del pueblo. Su visión se encuentra influenciada por el pensamiento liberal inglés, por Smith, por el individualismo y la importancia del desarrollo de patrimonio nacional, donde la riqueza es sinónimo de patria.

Alberdi será citado en ambas posturas para defender, claro está, la posición de cada una de ellas. En la de los jueces que consideraron la inconstitucionalidad, puede leerse:

Tanto el artículo 16 como el 20 de la Constitución Nacional tienen antecedente directo en el proyecto elaborado por Juan Bautista Alberdi y explicado en sus Bases. El artículo 16 de la Constitución Nacional (en adelante $\mathrm{CN}$ ) encuentra su paralelo en el artículo 17 del proyecto de Alberdi que dice en lo pertinente: "[T] odos son admisibles a los empleos. [...] La ley civil no reconoce diferencia entre extranjeros y nacionales". A su vez, el artículo $20 \mathrm{CN}$ lo reconoce en el 21 de dicho proyecto que establece: "[N]ingún extranjero es más privilegiado que otro. Todos gozan de los derechos civiles inherentes al ciudadano, y pueden comprar, vender, locar, ejercer industrias y profesiones, darse a todo trabajo, poseer toda clase de propiedades y disponer de ellas en cualquier forma; entrar y salir del país con ellas, frecuentar con sus buques puertos de la República, navegar en sus ríos y costas. (Párrafo de la sentencia ADC vs. GCBA)

De este modo, se hace referencia en la sentencia a "Las Bases..." de Alberdi. Específicamente, a los artículos vinculados al derecho al trabajo del que gozarían todos los extranjeros. La perspectiva alberdiana es de índole liberal ${ }^{9}$ en lo económico, pero no en lo político. Un sistema económico liberal era necesario sobre todo para el desarrollo nacional. Este será el objetivo que regirá lo postulado por Alberdi en todos los aspectos a los que se refiere en "Las Bases...", incluyendo la cuestión de los extranjeros y sus derechos. La totalidad de los postulados de Alberdi giran alrededor de la meta del impulso a la modernización. Así, la frase célebre "gobernar es poblar" se vincula con el fomento de la inmigración europea y el "transplante" de migrantes como fuerzas productivas que permitieran el desarrollo del país. El reconocimiento al acceso de puestos laborales constituiría parte de esta misma estrategia. Los valores a los 
que Alberdi apela en "Las Bases...” son los de la individualidad, el egoísmo: “...la idea de que cada ser humano es un sujeto independiente lanzado a su autorrealización”, para lo cual hay que dar garantías y derechos — principalmente, el de la propiedad privada-, que posibiliten el despliegue del accionar económico y productivo 10 (TERÁN, 2008, p. 2004). En este sentido, si bien Alberdi forma parte de aquellos que consideraron que la migración sería un aporte para el desarrollo del país, quienes debían conformar esa ola migratoria no serían migrantes cualesquiera, sino que “...el ejemplar por imitar se ciñe al continente europeo, y dentro de él, a Francia e Inglaterra, por motivos diversos en la valoración que alternativamente le merecen" (TERÁN, 2004, p. 24).

El español, el francés, el italiano, son, para formar el edificio político, como la piedra redonda; se resbalan y salen de su lugar. El inglés es quebrado y cortado para servir al todo, y por eso su libertad es tan sólida como su macadams. (Póstumos de Alberdi, Tomo VII citado en TERÁN, 2004, p. 95)

Cabe recordar que, para Alberdi, la mezcla de los pobladores locales con la que se "trasplantara" de Europa, es decir, el "crisol de razas", no sería negativo, sino que supondría una mejora en la civilización, a partir de la importación de un ethos económico que posibilitara la modernización de un país que, solo con sus elementos endógenos, no lograría llegar a nada. Sería necesario modificar la masa de la sociedad, por medio de la llegada de determinados extranjeros y el desarrollo del «momento económico», no así el político, que solo podría llegar luego de que el primero se hubiera concretado lo suficiente como para que el orden pudiera instaurarse. Es por ello que los derechos que se reconocerían a la masa de nativos y extranjeros serían aquellos que posibilitaran el desarrollo económico de sus capacidades productivas; pero no aun las políticas. ${ }^{11}$

Asimismo, los extranjeros gozarían de todos los derechos civiles, como también lo establece nuestra Constitución Nacional de 1853, y aún permanece así luego de la reforma de 1994. En relación a esto, si bien parece haber un consenso respecto a que puede asimilarse la categoría de derechos civiles, de la época histórica a la que referimos, al conjunto de derechos (excepto los políticos) de los que gozarían en igualdad nativos y extranjeros, puede evidenciarse en el fallo que la indeterminación de esta cuestión habilita a una interpretación más restrictiva de los derechos que se le reconocerían a los extranjeros en nuestro país. Así, puede leerse en la sentencia, primero una parte del artículo 21 de las Bases (en cursiva) y luego, la interpretación del juez:

Debe abrirles acceso a los empleos públicos de rango secundario, más que en provecho de ellos, en beneficio del país, que de ese modo, 
aprovechará de su aptitud para la gestión de nuestros negocios públicos y facilitará la educación oficial de nuestros ciudadanos por la acción del ejemplo práctico, como en los negocios de la industria privada. En el régimen municipal será ventajosísimo este sistema. Según se ve, hay una clara distinción entre el manejo de la noción de derechos civiles y el del acceso al empleo público. Tanto ello es así que Alberdi interpreta su cláusula relativa al empleo público, contenida en el artículo 21 que transcribí, de un modo más limitado que el que podría indicar una lectura ingenua del párrafo que destaqué con negrita. A la luz de lo que aquí dice, dicho párrafo puede leerse, sin temor a errar, en el sentido de que la ley no puede excluir al extranjero naturalizado por el solo motivo de haber nacido fuera del territorio nacional; pero, no está diciendo que no puede excluir al extranjero que no adopta la nacionalidad; siempre hablando del empleo público, porque está claro que no puede obligarlo a tomar dicha nacionalidad, ni tampoco excluirlo de los derechos civiles por no adoptarla. (Párrafo de la sentencia ADC vs. GCBA)

Continúa afirmando el juez:

...la expresión "derechos civiles" no puede ser entendida de modo que alcance a todo derecho que no tenga naturaleza política. Derechos civiles eran, y son, los garantizados por las leyes civiles. A su vera, podían distinguirse, como es hoy usual distinguir, derechos subjetivos públicos, uno de los cuales podía ser el acceso al empleo estatal. Suponer un ámbito más amplio para los derechos civiles implica olvidar que la voluntad del constituyente fue extender las mismas garantías del Tratado de 1825 a otros extranjeros, pero no extender el universo de garantías. Ese universo estuvo definido teniendo en mira asegurar a los extranjeros un tratamiento legislativo igualitario para los recursos que introdujeran al país, pero no un acceso a los recursos nacionales. Esto es así con mayor razón cuando se trata de recursos siempre limitados; en el caso, porque existe un número de plazas limitado directa o indirectamente por la ley. Si alguna duda generaba el texto del art. 21 del proyecto de Alberdi, ella se disipa con la eliminación, en el texto del art. 20 de la Constitución Nacional, de la referencia al empleo. (Párrafo de la sentencia ADC vs. GCBA)

La alusión a la Constitución, como ley fundamental, y a sus referentes intelectuales, también puede ser funcional a una lógica excluyente, sobre todo cuando, como se lee en el párrafo anteriormente citado, se trata de fundamentar el argumento de los “recursos siempre limitados del Estado". Clérico y Schvartzman (2007, 
p. 349) dicen que esta interpretación de lo propuesto por Alberdi se enmarca en una perspectiva originalista de la Constitución y que "...la aplicación exclusiva de este canon de interpretación suele ser atribuido a posiciones de interpretación constitucional conservadora”.

También este artículo debe ser examinado a la luz de los pasajes transcriptos de las Bases. Mientras el texto y sus antecedentes están indicando que fue vocación de sus redactores abrir la administración pública a los habitantes no ciudadanos, no es dudoso, al mismo tiempo, que ven en la condición de extranjero una razón para poner límites al acceso a ciertos cargos que podríamos llamar sensibles.

Las menciones a "empleos sensibles" que requieren el "compromiso con la Nación" recuerdan la centralidad del Estado y sus instituciones como organizadoras de la sociedad. Así, “... el Estado es una asociación de dominación de carácter institucional” (WEBER, 2007, p. 94) en la que se monopolizan diversas funciones (educativas, judiciales, represivas, etc.) a los fines de pautar un orden. En el caso de los extranjeros, desde la redacción de nuestra Constitución Nacional y las sucesivas normativas y medidas tomadas por los gobiernos, se instauró un modo de concebir al migrante o bien como el que traería, por medio de la mezcla, de la imitación y de sus prácticas, la civilización; o bien como el que aportaría la fuerza de trabajo necesaria para el despliegue de la producción de riquezas; o bien, el "chivo emisario" al que culpar por los conflictos propios del desarrollo de un modo de producción capitalista de clases. En suma, el Estado ha calificado y clasificado a los migrantes a partir de una lógica funcional que repercutió y repercute aún hoy en los modos como nos representamos a los extranjeros, así como consecuentemente, el lugar vulnerable que han ocupado dentro de la configuración social.

A modo de conclusión, podemos decir entonces que confluyen, en los elementos empleados para los argumentos desarrollados en la sentencia, lo que Terán (2008, p. 104) llamó, dos tipos de nacionalismos y que marcaron el proceso de construcción del Estado Nacional Argentino. Haciendo referencia a esos elementos del pasado, Cohen (2009, p. 20) sostiene que existen "huellas históricas" que resignificadas atraviesan las relaciones sociales actuales:

A lo largo de este, aproximadamente, siglo y medio pudo haberse constituido el país como una sociedad intercultural rica en diversidad étnica, con pueblos originarios, migrantes externos de origen latinoamericano, europeo, africano y asiático. Sin embargo, no se optó por esta alternativa, siempre el modelo predominante fue el de constituir una sociedad excluyente y hacedora de una obsesión, considerar que para construir su 
identidad nacional debía confrontar con su propio origen, más aún debía negarlo en su calidad de tal. El examen de admisión del que habla Bauman [refiere a la idea sobre el test de pertenencia permanente y de nunca acabar al que el Estado somete a los extranjeros] quizá pueda aprobarse en el futuro, pero para ello habrá que romper con estos puentes que aún perduran desde la segunda mitad del siglo XIX.

En suma, lo grave no sería lo que aquel ideario postulaba, ya que el mismo debe analizarse en relación al contexto histórico al que pertenece, no queriendo decir con esto que este fuese el único pensar de la época. No obstante, puede decirse, que lo preocupante es que aquellas perspectivas sean trasladadas al día de hoy, cuando la cuestión del reconocimiento, el respeto por la diversidad y los derechos humanos se presentan como un valor central en las sociedades actuales, además de verse reflejados en nuestra Constitución a partir de su reforma en el año 1994.

\section{CONCLUSIONES}

En las sentencias no solo se toma una decisión respecto a determinado conflicto, sino que además su desarrollo incluye una "puesta de escena" que se materializa principalmente en los argumentos que los jueces especifican para fallar en el sentido que lo hacen. Es decir, son una "representación para otros" (BARRERA, 2012, p. 130). En este sentido, el discurso — que se plasma en el escrito judicial— es una declaración para los demandantes, los abogados defensores y litigantes, otros miembros de la "familia judicial", futuros integrantes del sistema judicial y para la sociedad presente y futura, en tanto muchos de ellos sientan jurisprudencia o doctrina. En las sentencias, además, se ejerce una violencia simbólica, en el sentido de Bourdieu, y las decisiones del juez tienen una verdadera función de invención (BOURDIEU, 2000, p. 177). A partir de las sentencias, se dictamina — en estos casos — cuál es el grado de reconocimiento de derechos de los no nacionales. En el caso analizado, los fundamentos, también establecen —reforzando imaginarios sociales y de sentido común — ideas, imágenes acerca de los extranjeros como ciudadanos, sus obligaciones y niveles de "merecimiento" de determinados derechos tanto civiles como económicos y sociales.

El resultado del fallo fue que se rechazara el pedido de inconstitucionalidad, contradiciendo una serie de precedentes judiciales a favor de la igualdad entre nativos y migrantes. No obstante, luego, la Legislatura aprobó la ley 1696, que, finalmente, modificó el estatuto en cuestión, permitiendo a los docentes extranjeros acceder al puesto de maestros de escuelas públicas primarias de la Ciudad Autónoma de Buenos Aires (CABA). De este modo, sería el Poder Legislativo y no el Judicial el que reconocería los derechos de los maestros extranjeros que pretendieran ejercer su profesión en la mencionada jurisdicción. De esta manera, la Ley 1696 modificó las condiciones 
de acceso a la docencia de los extranjeros estipulando con fuerza de ley que para la misma se debe:

a) Ser argentino nativo, por opción, naturalizado o extranjero. En todos los casos dominar el idioma castellano. En el caso que el aspirante sea ciudadano extranjero deberá acreditar: 1 - la existencia de título suficiente que lo habilite para el ejercicio de la actividad de que se trate; 2 - el cumplimiento de los requisitos previstos por la Ley Nacional de Migraciones para su residencia en el país; y 3 - A los efectos de esta ley, podrán ser equiparados a los argentinos nativos los hijos de por lo menos un progenitor argentino nativo, que circunstancialmente hubieran nacido en el exterior con motivo del exilio o radicación temporaria de su familia, y tuvieran pendiente la tramitación para la obtención de la ciudadanía. ${ }^{12}$

No obstante este hecho, lo que interesó analizar una sentencia, en tanto modo privilegiado de transmisión de decisiones del Poder Judicial. Dicha decisión, que contradecía la jurisprudencia acerca de ciertos derechos de migrantes (que no sin resistencias y contramarchas había logrado desarrollarse en el país), permitió visibilizar la persistencia de discursos y representaciones sociales ligadas a la identidad nacional y a su asociación con la existencia de distinciones en el reconocimiento de derechos.

De este modo, el señalamiento de este tipo de casos debe encender las alarmas, para quienes consideramos de suma relevancia el progresivo avance de la igualdad de derechos entre todos los seres humanos. En este sentido, es que no debe ser ignorada la gravedad que implica, por sus consecuencias de regresividad en materia de derechos humanos, los intentos — como el analizado en las páginas precedentes — de establecer diferencias en el reconocimiento de derechos entre nativos y migrantes, basándose en distinciones que resultan contradictorias a los principios de igualdad, progresividad, universalidad e integrabilidad de los derechos humanos.

NOTAS

1 Esta línea de trabajo, que focaliza en la indagación y análisis de las representaciones sociales de los nativos sobre los migrantes externos, ha sido desarrollada en el marco de una serie de proyectos de investigación dirigidos 
por el Dr. Cohen, con sede en el Instituto de Investigaciones Gino Germani de la Universidad de Buenos Aires, en los cuales la autora del presente artículo ha participado.

2 Causa n. 3103/04 "Asociación por los Derechos Civiles (ADC) c/ GCBA s/ acción declarativa de inconstitucionalidad”. 31 de marzo de 2005.

3 Se trata de una organización no gubernamental entre cuyas tareas principales están las de monitorear políticas públicas, promover reformas legales y realizar actividades de investigación. Asimismo, utiliza el litigio de interés de público como herramienta privilegiada para promover acciones concretas en el desarrollo de los derechos humanos. Para mayor información puede consultarse: http://www.adc.org.ar/\#

4 Expte. $\mathrm{n}^{\circ}$ 4172/05, “Asociación por los Derechos Civiles (ADC) c/ GCBA s/ acción declarativa de inconstitucionalidad", sentencia de fecha 9/8/2006. Disponible en: <http://www.adaciudad.org.ar/sitio/pdfs/fallos/ TSJ/Asociacion_Derechos_Civiles.2006.pdf $>$.

5 El texto completo del fallo se encuentra disponible en: http://www.tsjbaires.govs.ar/index.php? option $=$ com_flexicontent $\&$ view $=$ category $\&$ cid $=29 \&$ Itemid $=26$

6 Se toma la definición de representaciones sociales de Jodelet (1986), es decir, se trata de un conocimiento práctico que al dar sentido a acontecimientos y actos que terminan por sernos habituales resulta ser un conocimiento que participa en la construcción social de la realidad.

7 Para ampliar esta cuestión ver: Treacy (2011); Rodríguez Miglio y Toledo (2009); Morales (2012); Abramovich (2009).

8 Este término implica un enfoque que estudia las migraciones “...en términos relativos o relacionales, considerando su historia e incluyendo, en su abordaje, el nuevo proceso que se gesta con la construcción de su extranjeridad al interior de la trama de relaciones sociales que lo contiene en la sociedad receptora. Este abordaje relacional del migrante externo incluye al nativo como actor social que participa en el proceso de otorgar sentido a la presencia del migrante, sentido que no siempre es reconocido por este último, sentido que puede ubicarlo en condiciones desiguales respecto el nativo. Es un sentido que puede crear condiciones de tensión y hasta de conflictividad". (COHEN, 2004, s/p)

9 "Siendo el desarrollo y la explotación de los elementos de riqueza que contiene la República Argentina el principal elemento de su engrandecimiento y el aliciente más enérgico de la inmigración extranjera de que necesita, su Constitución debe reconocer, entre sus grandes fines, la inviolabilidad del derecho de propiedad y la libertad completa del trabajo y de la industria. Prometer y escribir estas garantías no es consagrarlas. Se aspira a la realidad, no a la esperanza. Las constituciones serias no deben constar de promesas, sino de garantías de ejecución. Así la Constitución argentina no debe limitarse a declarar inviolable el derecho privado de propiedad, sino que debe garantizar la reforma de todas las leyes civiles y de todos los reglamentos coloniales vigentes, a pesar de la República, que hacen ilusorio y nominal ese derecho. Con un derecho constitucional republicano y un derecho administrativo colonial y monárquico, la América del Sud arrebata por un lado lo que promete por otro: la libertad en la superficie y la esclavitud en el fondo". (Las Bases, Alberdi)

10 En este sentido, el nacionalismo constitucionalista puede ser compatible con una perspectiva liberal que coloque al individuo por encima de todo. En cambio, entra en contradicción con el nacionalismo culturalista, ya que éste ubica a la idea de comunidad nacional por encima de los intereses de cada individuo.

11 En las Bases, al postular la "República posible", Alberdi es claro al proclamar un sistema de gobierno elitista, al menos para el momento y el "tipo" de población con el que contaba el país, por ejemplo, así se refiere a la cuestión del sufragio universal: "la universalidad de los sufragantes carece de toda educación, de toda inteligencia de las prácticas del sufragio verdadero [...] libres al modo de los menores y de los incapaces del orden civil, esas multitudes tituladas soberanas eligen como eligen las mujeres y los menores de edad: lo que se les hace elegir. (Escritos Póstumos de Alberdi, Tomo IV, citado en TERÁN, 2004, p. 92)

12 Disponible en: <http://www.ciudadyderechos.org.ar/derechosbasicos_l.php?id=10\&id2=139\&id3=665\#>. 


\section{REFERENCIAS}

ABRAMOVICH, VS. El rol de la justicia en la articulación de políticas y derechos sociales. In: ABRAMOVICH, VS; PAUTASSI, L. Revisión judicial de políticas sociales: estudio de casos. Buenos Aires: Del Puerto, 2009.

ALBERDI, J. B. Bases y puntos de partida para la organización política de la República Argentina. La Plata: Terramar, 2007. ARCHENTI, N. Estudio de caso/s. In: A. MARRADI, N. ARCHENTI; J. I. PIOVANI, Metodología de las ciencias sociales. Buenos Aires: Emecé Editores, 2007.

BALIBAR, E. La forma nación: historia e ideología. In: E. Balibar, \& I. Wallerstein, Raza, Nación y Clase. Madrid: IEPALA, 1988.

. Nombres y lugares de la verdad. Buenos Aires: Ed. Nueva Visión, 1995.

Violencias, identidades y civilidad. Barcelona: Gedisa, 2005.

BARRERA, L. La Corte Suprema en escena. Una etnografía del mundo judicial. Buenos Aires: Siglo XXI editores, 2012. BAUMAN, Z. Modernidad y ambivalencia. In: GIDDENS, A. LUHMANN, N.; BECK U., Las consecuencias perversas de la modernidad. España: Anthropos, 1996.

La globalización. Consecuencias humanas. Brasil: FCE, 1999.

Vidas desperdiciadas: la modernidad y sus parias. Buenos Aires: Paidós, 2005.

BERTONI, L. A. Patriotas, cosmopolitas y nacionalistas. La construcción de la nacionalidad argentina a fines del siglo XIX. Buenos Aires: FCE, 2007.

BOURDIEU, P. Poder, derecho y clases sociales. Bilbao, España: Ed. Desclée de Brouwer, [2000] 2001. . Elementos para una sociología del campo jurídico en BOURDIEU, P. \& TEUBNER, G., La fuerza del derecho. Colombia: Siglo del Hombre, 2000. Cosas dichas. Barcelona: Gedisa, 1996.

La dominación masculina. Barcelona: Anagrama, 2000.

Espíritus de Estado. Génesis y estructura del campo burocrático en Revista Sociedad, Facultad de Ciencias Sociales (UBA), 2002. Disponible en: <http://www.uruguaypiensa.org.uy/imgnoticias/1042.pdf> CLÉRICO, L.; ALDAO, M. La igualdad como redistribución y como reconocimiento: derechos de los pueblos indígenas y Corte Interamericana de DD.HH. Estudios Constitucionales, 9(1), 2011.

CLÉRICO, L.; RONCONI, L.; \& ALDAO, M. Hacia la reconstrucción de las tendencias jurisprudenciales en América Latina y el Caribe en materia de igualdad: sobre la no-discriminación, la no-dominación y la redistribución y el reconocimiento. Revista Direito GV, 9(1), 2013.

CLÉRICO, M.; SCHVARTZMAN, S. "Repetto" revisitado: a propósito del fallo del Tribunal Superior de la Ciudad de Buenos Aires sobre el acceso a la docencia en el caso de extranjeros. In: M. Alegre, \& R.

Gargarella, El derecho a la igualdad. Buenos Aires: Lexis Nexis, 2007.

COHEN, N. No es sólo cuestión de migrantes: migraciones externas y exclusión social. In: Goinheix. Conflictos y expresiones de la desigualdad y la exclusión en América Latina. Buenos Aires: El Aleph, 2009. El inmigrante externo y el ámbito laboral. Puertas adentro: la inmigración discriminada, Buenos

Aires: IIGG, FCS, UBA, 2004.

DE SOUSA SANTOS, B. A crítica da razão indolente. San Pablo: Cortez Editora, 2009.

DEVOTO, F. Movimientos migratorios: historiografía y problemas. Buenos Aires: Centro Editor de América Latina, 1992. Historia de la inmigración en la Argentina. Buenos Aires: Sudamericana, 2003.

DIAZ POLANCO, H. Elogio de la diversidad: globalización, multiculturalismo y etnofagia. México: Siglo XIX, 2006. DULITZKY, A. El principio de igualdad y no discriminación. Claroscuros de la Jurisprudencia Interamericana. Anuario de DD.HH. (3), 2007.

FELDFEBER, M. Las políticas de formación docente en los orígenes del sistema educativo argentino. Ponencia presentada en el III Congreso Iberoamericano de Historia de la Educación Latinoamericana. Caracas, 1996.

FRASER, N. Justicia social en la era política de la identidad. En N. Fraser, \& A. Honneth, ¿Redistribución o reconocimiento?: Un debate político-filosófico. Madrid: Morata, s.f.

GONZÁlEZ, A.; PLOTNIK, G. ¿De la homogeneidad a la diversidad? La construcción de la otredad del migrante externo en el ámbito educativo. Propuesta Educativa, 2011.

HALL, S. ¿Qué es "lo negro" en la cultura popular negra?, 2003. Obtenido de <http://www.biblioteca.org.ar/ libros/1899.pdf $>$.

JODELET, D. La representación social: fenómenos, concepto y teoría. En S. Moscovici, Psicología social. Barcelona: Paidós, 1986.

MARRADI, A.; ARCHENTI, N.; PIOVAnI, J. Metodología de las Ciencias Sociales. Buenos Aires: Emecé, 2007. MORALES, D. Derechos Humanos de los migrantes en la Argentina. Apuntes sobre nuevas perspectivas jurisprudenciales. (D. T. Legal, Ed.) Revista de Derecho Público, 1(2), septiembre de 2012.

PUCCIARELLI, A. ¿Crisis o decadencia? Hipótesis sobre el significado histórico de algunas transformaciones 
recientes de la sociedad argentina. Estudios Sociológicos del Colegio de México, XVII(49), enero-abril de 1999. RODRÍGUEZ MIGLIO, E.; TOLEDO, L. Jurisprudencia argentina en materia de derechos de migrantes. In: CERnADAs CERIANi, P.; FAVA, R. Politicas migratorias y Derechos Humanos. Remedios de Escalada, Pcia. de Buenos Aires.: UNLa, Universidad Nacional de Lanús, 2009.

SABA, R. Desigualdad estructural. Revista Derecho y Humanidades (11), 2005.

STRAUSS, A.; CORBIN, J. Bases de la investigación cualitativa: técnicas y procedimientos para desarrollar la teoría fundamentada. Colombia; Universidad de Antioquia, 2002.

TERÁN, O. Las palabras ausentes: para leer los escritos póstumos de Alberdi. Buenos Aires: FCE, 2004.

Historia de la ideas en la Argentina. Diez lecciones iniciales, 1810-1980. Buenos Aires: Siglo XIX, 2008.

TERRÉN, E. La ironía de la solidaridad: cultura, sociedad civil y discursos sobre el conflicto racial de El Ejido. REIS (102), 2003.

TREACY, G. F. Categorías sospechosas y control de constitucionalidad. Lecciones y Ensayos (89), 2011. WEBER, M. La politica como profesión. Madrid: Espasa Calpe, 2007.

ZIZEK, S. En defensa de la intolerancia. Madrid: Ediciones Sequitur, 2008.

Anahi Patricia González

Merlo - Provincia de Buenos Aires - Argentina anahipgonzalez@gmail.com
Becaria Post-doctoral en el Consejo Nacional de INVESTIGACIONES CIENTÍFICAS Y TÉCNICAS, (CONICET) CON SEDE EN EL INSTITUTO dE INVESTIGACIONES Gino GeRMANI.

Docente de la Facultad de Ciencias Sociales, UniversidAd de BUenos Aires. 